\title{
A Study of in vitro Scavenging Reactions of Acrylamide with Glutathione Using Electrospray Ionization Tandem Mass Spectrometry
}

\author{
Shengyun Cui, ${ }^{\dagger}$ Seung-Jin Kim, Sung-Chan Jo, ${ }^{\ddagger}$ Yong-Moon Lee, ${ }^{\S}$ and Yong-Ill Lee* \\ Department of Chemistry, Changwon National University, Changwon 641-773, Korea. *E-mail: yilee@sarim.changwon.ac.kr \\ ${ }^{\dagger}$ Department of Chemistry, Yanbian University, Yanji 133002, China \\ *Center for Biomarker Analysis, The University of Tennessee, Knoxville, TN 37932, USA \\ ${ }^{\S}$ College of Pharmacy, Chungbuk National University, Cheongju 361-763, Korea \\ Received December 22, 2004
}

\begin{abstract}
A combination of electrospray ionization and tandem mass spectrometry was used to characterize the scavenging reactions of acrylamide (AA) in the presence of glutathione (GSH) in vitro. In the presence of GSH, AA was deactivated effectively and scavenged by reactions consuming small amount of GSH. Reaction products and structural information were identified using collision-induced dissociation (CID) in an ion trap mass spectrometer. In the mixture of GSH and AA, significant increase in abundance of fragment ion peak was observed at $\mathrm{m} / \mathrm{z} 233$, which was identified as [Cys-Glu] $]^{+}$, formed by the elimination of glycine moiety of GSH. GSH also contributes to the AA scavenging reaction by conjugating with AA through the sulfhydryl group in cysteine moiety. The probable scavenging reaction pathway of AA in the presence of GSH has been proposed based on the CID experimental data.
\end{abstract}

Key Words : Glutathione, Acrylamide, Electrospray ionization, Food safety

\section{Introduction}

Acrylamide (AA), a reactive vinyl monomer used in the synthesis of polyacrylamide products, is a neurotoxin with an effect on both central and peripheral nervous system. It gives rise to an increased cancer incident and reproductive disruption in animal tests and is classified as a carcinogen to human. ${ }^{1-5}$ In April 2002, a large amount of AA was detected by Swedish researchers in baked and fried starch-rich foods, notably potato chips and French fries, at levels of 30-2,300 $\mathrm{ppb}$. This finding gave rise to serious concern in food safety and intrigued many researchers mostly in understanding how the cancer-suspected agent is introduced during food preparations. ${ }^{6-10}$ Further studies elucidated that Maillard browning reaction products derived from glucose and asparagines which are the major components in potatoes and cereals are responsible for the formation of AA during the food processing. ${ }^{11-14}$ Recently, British scientists, La Mucci et $a l .{ }^{15}$ reanalyzed a population-based Swedish case-control study encompassing patients with cancer in the large bowel $(\mathrm{N}=591)$, bladder $(\mathrm{N}=263)$ and kidney $(\mathrm{N}=133)$ compared to 538 healthy controls in order to assess dietary AA by linking extensive food frequency data with AA levels in certain food items. They could not find any correlation or convincing trend in cancer of the bowel, bladder, or kidney among frequent consumers of 14 different food items with a high (range 300-1200 $\mu \mathrm{g} \mathrm{kg}^{-1}$ ) or moderate (range 30-299 $\mu \mathrm{g}$ $\mathrm{kg}^{-1}$ ) AA content. Likewise, when they analyzed quartiles of known dietary acrylamide intake, no association was found with the cancers. Instead, they could see some contradicting results.

This discrepancy seems to indicate that there exists an effective scavenging or blocking reactions before AA

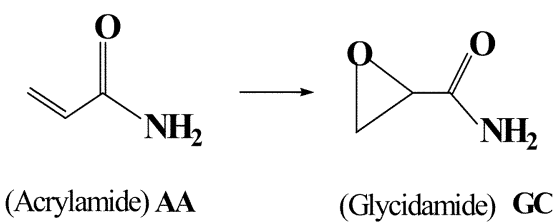

Scheme 1. Structures of acrylamide (AA) and glycidamide (GC).

ingested with foods binds to the DNA producing genotoxic or mutagenic substances in vivo. Recent study indicated that glycidamide (GA) (Scheme 1), the reactive epoxide metabolite of AA, is mutagenic. ${ }^{16}$ Most in vivo researches have shown that a genotoxic mechanism involving GA is more consistent although some suggestions have been made for hormonally mediated mechanisms of AA carcinogenicity in the rat. ${ }^{17}$

AA was also known as a mutagenic substance in vivo, but the evidence for direct genotoxicity mediated by AA has been limited. Therefore, some of the reactions including the deactivation or scavenging of AA by antioxidants in daily diet or formed endogenously might exist and have an anticancer activity by inhibiting the formation of GA or scavenging AA before it forms carcinogenic substances.

Tri-peptide glutathione ( $\gamma$-glutamyl-cysteinyl-glycine) (GSH) is an endogenous antioxidant of great importance and found in foods or plants as well. GSH is widely distributed in biological cells and involved in many physiological phenomena including protecting cells against oxidative damage. $^{18-22}$

There has been a long tradition of using mass spectrometry to explore organic reactions and this has been strengthened by the advent of electrospray ionization (ESI). ESI constitutes a useful means to interrogate native chemical 
systems in solution phase, mainly by providing molecular weight information..$^{23-25}$ In this work, ESI mass spectrometry was employed to investigate the scavenging reactions of AA in the presence of GSH in vitro. Conjugation products and structural information were identified using gas-phase collision-induced dissociation (CID) by an ion trap mass spectrometer. The attempt to apply mechanistic principles to the product ions observed in the $\mathrm{MS}^{\mathrm{n}}$ spectra of the compounds has been performed for different concentration ratios of AA/GSH. The data presented suggest that GSH directly conjugated with part of AA monomers and oligomers formed between AA and its degraded fragments via sulfhydryl group in cysteine moiety and effectively scavenged AA monomers to the small molecular fragments with the consumption of small amount of GSH.

\section{Experimental Section}

Acrylamide (AA), glutathione (GSH, reduced form) were purchased from Aldrich and used as obtained. The stock solutions $(2 \mathrm{mM})$ of acrylamide and glutathione were mixed with different molar ratios in deionized water and methanol (1:1) just before the mass spectrometric measurements. The identification of conjugation products was performed using Thermo Finigan LCQ Advantage ion trap mass spectrometer equipped with electrospray ionization.

For sample injections, the instrument syringe pump was used at flow rate of $2 \mu \mathrm{L} / \mathrm{min}$. The instrumental operation conditions were as follows; spray voltage, $4.58 \mathrm{KV}$; source current, $0.48 \mu \mathrm{A}$; sheath gas flow rate, $19.43 \mu \mathrm{L} / \mathrm{min}$; capillary voltage, $9.44 \mathrm{~V}$; capillary temperature, $100{ }^{\circ} \mathrm{C}$; and tube lens voltage, $55 \mathrm{~V}$. For the CID experiments, the collision energies were applied between 0.57-0.92 V until the relative abundance of selected ion was less than $20 \%$. Experiments were performed in positive-ion mode and optimized by Xcalibur software before the experiments. All of the MS experiments in this work have been carried out under the optimized instrument conditions. All the mass spectra reported are averaged over at least 30 consecutive scans.

\section{Results and Discussion}

ESI Mass Spectra of GSH. Figure 1 shows the ESI full scan mass spectrum generated in positive ion mode using an aqueous methanol solution $(50 \% / 50 \%)$ containing $1 \mathrm{mM}$ GSH. Dominant protonated $[\mathrm{M}+\mathrm{H}]^{+}$molecular ion peak of GSH was observed at $\mathrm{m} / \mathrm{z} 308,[\mathrm{GSH}+\mathrm{H}]^{+}$, followed by the proton-bound dimer of GSH at $\mathrm{m} / \mathrm{z} 615,[2 \mathrm{GSH}+\mathrm{H}]^{+}$, and small fragments ion peaks were also observed at $\mathrm{m} / \mathrm{z} 162$, $\mathrm{m} / \mathrm{z} 179$ and $\mathrm{m} / \mathrm{z} 233$. Multiple stage CID spectra $\left(\mathrm{MS}^{\mathrm{n}}\right)$ for the protonated molecular ion of GSH at $\mathrm{m} / \mathrm{z} 308$ using activation conditions chosen to maximize fragment ion abundances were shown in Figure 2. The most abundant fragment ion at the previous stage was selected for further collisional activation. As shown in Figure 2(a), dominant peaks at $\mathrm{m} / \mathrm{z} 179,[\mathrm{Cys}-\mathrm{Gly}]^{+}$, in the first stage of CID mass spectrum indicated that peptide bonding in the GSH easily fragments by the loss of glutamate in the gas phase. Another peptide bond is also fragmented by the loss of glycine moiety and represented by the peak at $\mathrm{m} / \mathrm{z} 233$, [Glu-Cys] ${ }^{+}$, though in low abundance. From the multistage CID spectra in Figure 2(b-c), the fragment ion peaks at m/z 162, m/z 144, and $\mathrm{m} / \mathrm{z} 116$ were generated by the dissociation of fragment ion at $\mathrm{m} / \mathrm{z} 179$. Whole fragmentation pathway of GSH is described in Scheme 2. As shown in Scheme 2, peptide bonds in GSH are easily broken with collisional activation and formed main fragment ions at $\mathrm{m} / \mathrm{z} 179,[\mathrm{Cys}-\mathrm{Gly}]^{+}$, and $\mathrm{m} / \mathrm{z}$ 233, [Cys-Glu] $]^{+}$. Relative higher abundance of the ion peaks at $\mathrm{m} / \mathrm{z} 179$ indicated that peptide bond between glutamate and cysteine cleavages more easily in the gas phase than the other peptide bonds in GSH.

ESI Mass Spectra in the Mixture of GSH and AA. GSH has been found in foods as well as in diverse kinds of plants including edible plants and vegetables. ${ }^{26,27} \mathrm{GSH}$ is also proposed as a main substance for AA metabolism through enzymatic reactions in vivo. ${ }^{2}$ The study on the direct reaction between glutathione and acrylamide in vitro is very

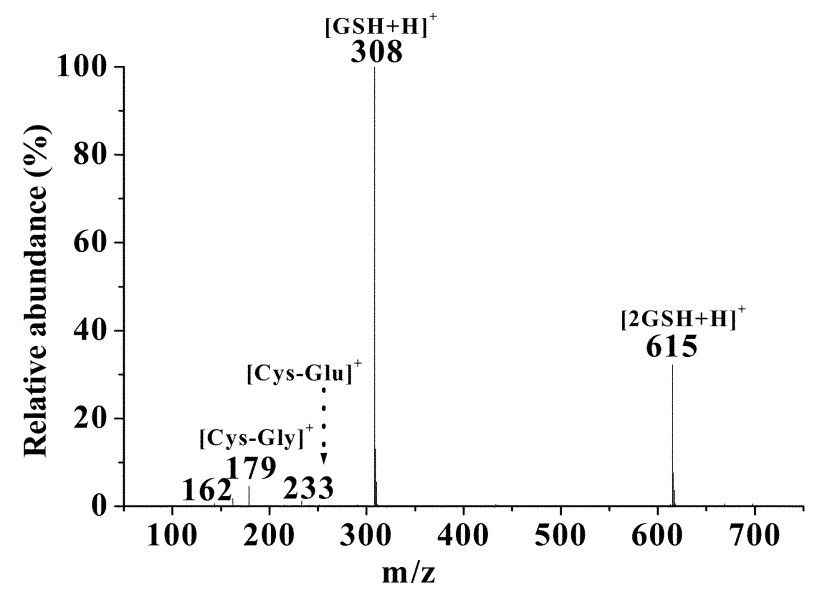

Figure 1. ESI positive ion mass spectrum of an aqueous methanol (50/50\%) solution containing $1 \mathrm{mM} \mathrm{GSH}$.

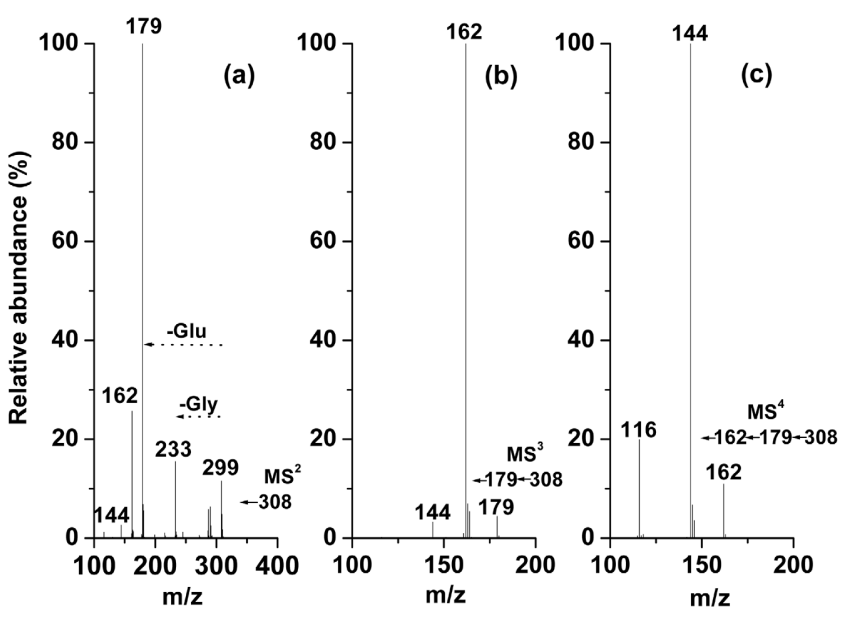

Figure 2. $\mathrm{MS}^{\mathrm{n}}$ product ion spectra $(\mathrm{n}=2(\mathrm{a}), 3(\mathrm{~b}), 4(\mathrm{c}))$ of protonated GSH molecular ion at $\mathrm{m} / \mathrm{z} 308$. 


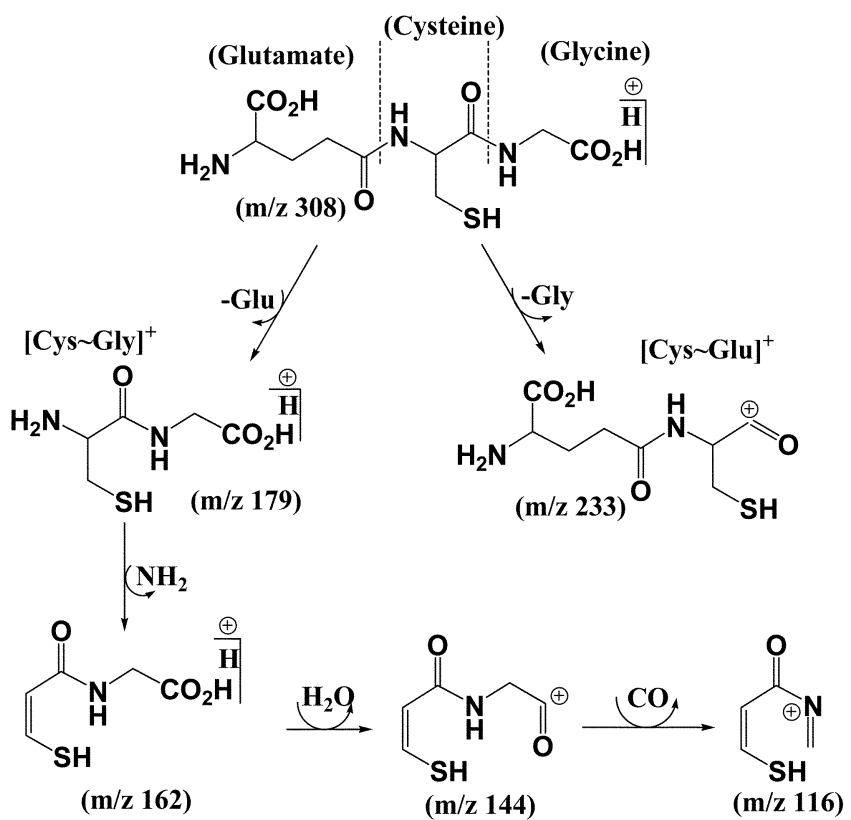

Scheme 2. Proposed fragmentation pathways of protonated GSH.

important for evaluating possible scavenging reactions of acrylamide during dietary intake of glutathione. In order to investigate the possible interaction between GSH and AA, mixtures of the two substances with different ratios were infused to ESI mass spectrometer using a syringe pump at a flow rate of $5 \mu \mathrm{L} / \mathrm{min}$. Figure 3 shows the full mass spectra obtained from the mixture of GSH and AA with $1: 1(1 \mathrm{mM}$ : $1 \mathrm{mM})$ and $1: 3(1 \mathrm{mM}: 3 \mathrm{mM})$ molar ratios. Several new ion peaks, such as at $\mathrm{m} / \mathrm{z} 143, \mathrm{~m} / \mathrm{z} 233, \mathrm{~m} / \mathrm{z} 379$ and $\mathrm{m} / \mathrm{z} 488$ were generated in contrast to those of pure GSH shown in Figure 1. And also, the newly generated conjugated ion peaks gradually increased as the relative amount of AA monomer increased. Though not shown here, the spectrum of a pure AA solution showed the typical protonated molecular ion peak at $\mathrm{m} / \mathrm{z} 72$ and various oligomer ion peaks including proton-bound dimer at m/z 143 in the higher mass range due to the polymerization of AA during electrospray. The polymerization made the experiment difficult when the highly concentrated AA solutions were used because polymer precipitates inside the electrospray needle and blocks capillary. However, a protonated molecular ion peak of $\mathrm{AA}$ at $\mathrm{m} / \mathrm{z} 72$ was not detected in the presence of GSH and no apparent polymerization reaction of AA monomers was occurred. This unusual observation indicates that AA
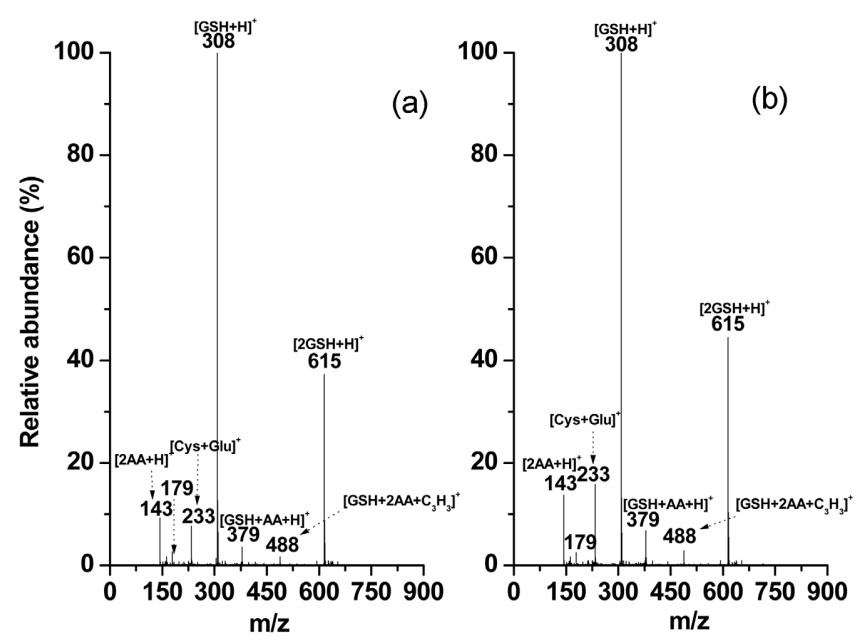

Figure 3. ESI positive ion mass spectra of the mixture of GSH and AA with the molar ratio of $1 \mathrm{mM}: 1 \mathrm{mM}$ (a) and $1 \mathrm{mM}: 3 \mathrm{mM}$ (b). The major ions are labeled.

monomer was deactivated for the polymerization reaction by GSH and then transformed to other soluble reaction products. The low abundance of the conjugated ion peaks and the dominantly high abundances of GSH ion peaks remained even in the $1: 3$ molar ratio indicated that most AA monomers might be degraded to the small fragments in the presence of GSH, which is not detectable under our experimental conditions. For further confirmation of the scavenging reactions, the mixture solution of GSH and AA was incubated at room temperature for 4 hours and recorded full mass spectrum. Important ions generated in the mixture solutions were summarized in Table 1 and compared to those without incubation. Similar pattern of the mass spectrum was obtained with only little differences in ion intensity.

CID mass spectra were taken for structural characterization of the interaction products generated in the mixture of GSH and AA and shown in Figure 4. As can be seen in Figure 4, a protonated dimeric adduct ion at $\mathrm{m} / \mathrm{z} 143$ dissociated to a typical protonated AA molecular ion peak at $\mathrm{m} / \mathrm{z} 72,[\mathrm{AA}+\mathrm{H}]^{+}$, and further dissociated ion at $\mathrm{m} / \mathrm{z} 55$ by the loss of ammonium from the protonated AA monomer. CID mass spectrum of the ion at $\mathrm{m} / \mathrm{z} 233$, [Glu-Cys] $]^{+}$, was initiated by eliminating glycine moiety from GSH as shown in Scheme 2, resulting in the main fragment ion peaks at $\mathrm{m} / \mathrm{z}$ 146, m/z 172, m/z 187 and m/z 217 (Fig. 4(b)). The ion at $\mathrm{m} / \mathrm{z} 379$ formed by the incorporation of AA to the sulfhydryl

Table 1. key ions in the full scan mass spectra of GSH and the mixture of GSH and AA with different molar ratios. The values in the brackets give the relative abundance as compared to the ion peak at $\mathrm{m} / \mathrm{z} 308$. *represent the results after incubations for 4 hrs

\begin{tabular}{lccccccc}
\hline \multicolumn{1}{c}{ Compounds } & {$[\mathrm{GSH}+\mathrm{H}]^{+}$} & {$[2 \mathrm{GSH}+\mathrm{H}]^{+}$} & {$[\mathrm{AA}+\mathrm{H}]^{+}$} & {$[\mathrm{Cys}-\mathrm{Gly}]^{+}$} & {$[\mathrm{Cys}-\mathrm{Glu}]^{+}$} & {$[\mathrm{GSH}+\mathrm{AA}+\mathrm{H}]^{+}$} & {$\left[\mathrm{GSH}+2 \mathrm{AA}+\mathrm{C}_{3} \mathrm{H}_{3}\right]^{+}$} \\
\hline GSH & $308(100)$ & $615(33)$ & & $179(4)$ & & & \\
GSH:AA (1:1) & $308(100)$ & $615(38)$ & $143(9)$ & $179(3)$ & $233(8)$ & $379(4)$ & $488(2)$ \\
GSH:AA* (1:1) & $308(100)$ & $615(39)$ & $143(0)$ & $179(7)$ & $233(2)$ & $379(0)$ & $488(0)$ \\
GSH:AA (1:3) & $308(100)$ & $615(45)$ & $143(14)$ & $179(3)$ & $233(16)$ & $379(7)$ & $488(3)$ \\
GSH:AA* (1:3) & $308(100)$ & $615(23)$ & $143(10)$ & $179(3)$ & $233(8)$ & $379(1)$ & $488(1)$ \\
\hline
\end{tabular}



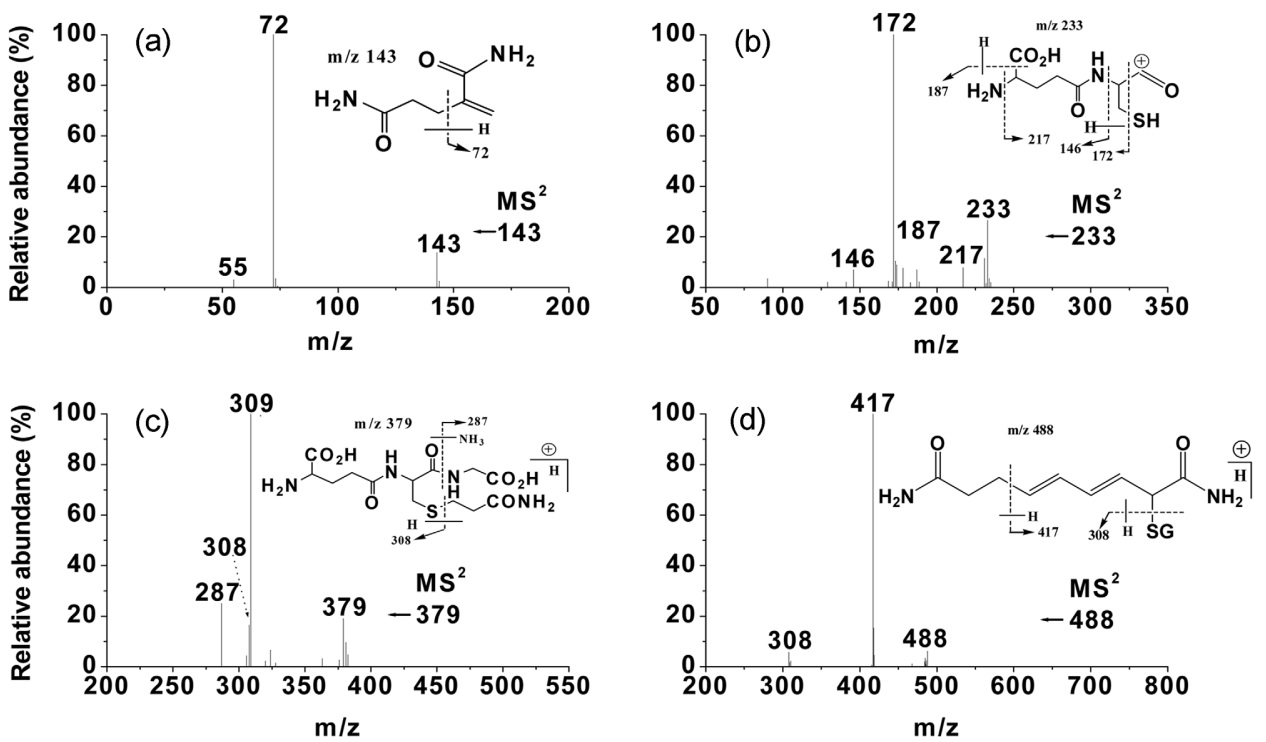

Figure 4. CID mass spectra of the reaction product ions at $\mathrm{m} / \mathrm{z} 143(\mathrm{a}), \mathrm{m} / \mathrm{z} 233(\mathrm{~b}), \mathrm{m} / \mathrm{z} 379$ (c) and $\mathrm{m} / \mathrm{z}$ 488(d) generated in the mixture of GSH and AA. The proposed structures of reaction product ions are shown in the figure.

group of GSH was isolated and then activated to reveal the main fragment ions at $\mathrm{m} / \mathrm{z} 308, \mathrm{~m} / \mathrm{z} 309$ and $\mathrm{m} / \mathrm{z} 287$. The fragment ion at $\mathrm{m} / \mathrm{z} 308$ was formed by the loss of conjugated AA (Fig. 4(c)). The formation of fragment ions at $\mathrm{m} / \mathrm{z} 309$ and $\mathrm{m} / \mathrm{z} 287$ is quite unusual, which might be formed through multi-step reactions as can be seen in Scheme 3. In the scheme, the fragmentation of the conjugated GSH product ion at $\mathrm{m} / \mathrm{z} 379$ was proposed to initiate as the terminal amide group of the glutamate is protonated by the acidic hydrogen of the neighboring carboxylic moiety. The abstracted hydrogen and formed ammonia group were further shifted to the carbon atom accompanied by the loss of neutral fragment. The fragmentation ion at $\mathrm{m} / \mathrm{z} 287$ was formed by the loss of both glycine moiety and ammonia as shown in Figure 4(c).

Dissociation of the ion at $\mathrm{m} / \mathrm{z} 488$ produced the two main fragment ion peaks at $\mathrm{m} / \mathrm{z} 417$ and $\mathrm{m} / \mathrm{z} 308$ (Fig. 4(d)). Two fragment ions at m/z 364 and m/z 378 were observed from further dissociation of isolated ion at $\mathrm{m} / \mathrm{z} 417$ by the loss of 39 Dalton and 53 Dalton, which might involve double-bond migration to the conjugated position followed by allylic cleavage. Therefore, the ion at $\mathrm{m} / \mathrm{z} 488$ might represent the conjugation of the GSH to the oligomers that was formed between AA monomer and degradation products of AA with diene substructure. Further evidence is obtained from a comparison of collision energy differences in CID experiments. For the ions at m/z $143[2 \mathrm{AA}+\mathrm{H}]^{+}, 0.37 \mathrm{~V}$ collision energy with the total amplitude of $5 \mathrm{~V}$ was applied for fragmentation, while $0.87 \mathrm{~V}$ for $\mathrm{m} / \mathrm{z} 233$ ion [glu-Cys] $]^{+}, 0.97$ $\mathrm{V}$ for $\mathrm{m} / \mathrm{z} 379$ ion $[\mathrm{GSH}+\mathrm{AA}+\mathrm{H}]^{+}$and $0.92 \mathrm{~V}$ for $\mathrm{m} / \mathrm{z} 488$ ion $\left[\mathrm{GSH}+2 \mathrm{AA}+\mathrm{C}_{3} \mathrm{H}_{3}\right]^{+}$were used. The low collision energy for the ion at $\mathrm{m} / \mathrm{z} 143[2 \mathrm{AA}+\mathrm{H}]^{+}$indicates that it is protonated non-covalent dimer formed by combining two AA molecules. It is well known that dimer ions generally

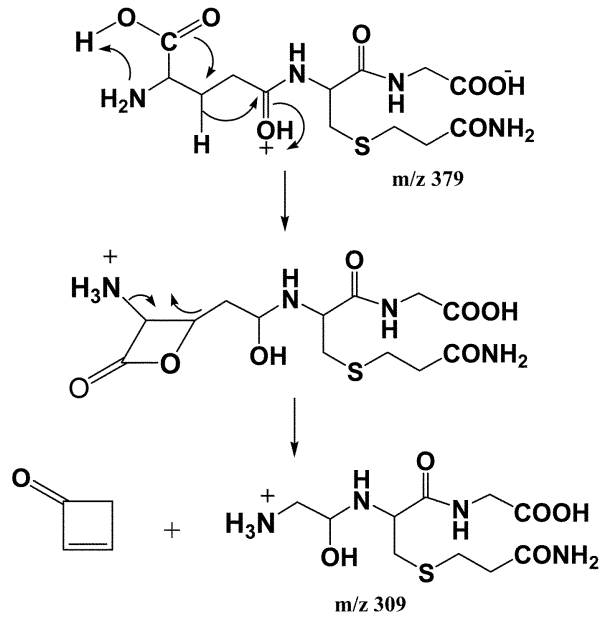

Scheme 3. Proposed structures of the product ions between GSH and AA at $\mathrm{m} / \mathrm{z} 379$ as well as the fragment ion at $\mathrm{m} / \mathrm{z}$ at 309 .

involve labile hydrogens in hydrogen bonds that hold the dimer together, which leads to the less collision energy in the ion trap for the fragmentation as compared to the fragmentation of covalently bonded ions.

The degradation/deactivation pathway of acylamide in vitro by GSH is mainly via the decomposition of glycine fragment of GSH. The glycine moiety can be eliminated more easily by the cleavage of peptide bonding in the presence of AA. The glycine in the solution is easily degraded by the Streck degradation to the strecker aldehyde and ammonia as well as carbon dioxide. The Streck degradation product, such as formaldehyde reacts with acrylamide, which leads to decomposition of the AA to small molecular fragments. Then, AA can be transformed to acrylate which is susceptible to consecutive decarboxylation and further total oxidation by the catalytic processes of 


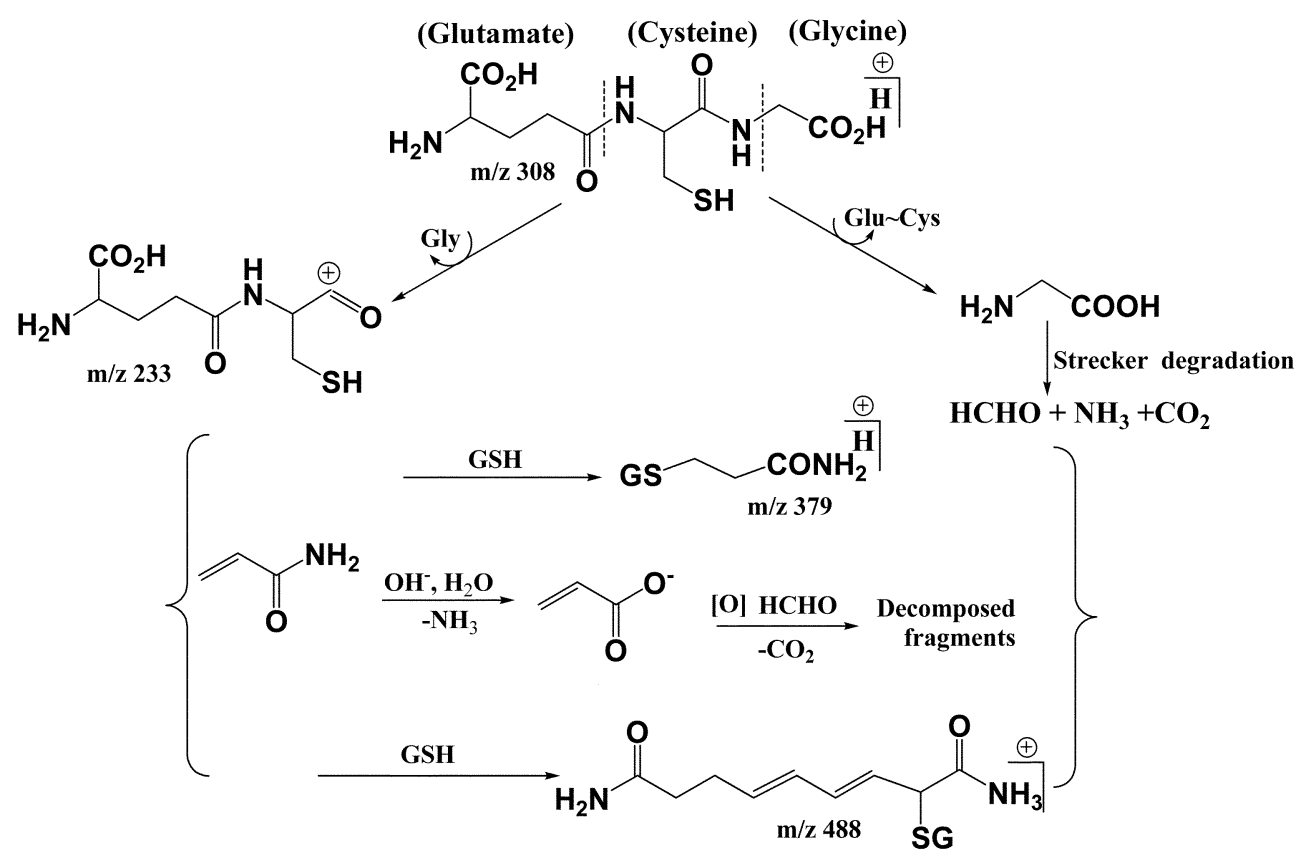

Scheme 4. Proposed scavenging reactions of AA in the presence of GSH.

degraded products of glycine. This scavenging reaction similar to the catalytic total oxidation of AA in the presence of water via the formation of acrylate. ${ }^{28}$ Glu-Cys species at $\mathrm{m} / \mathrm{z} 233$ might also be degraded by the Streck degradation in the solution mixture and the degraded products also contributes to the scavenging reaction of $\mathrm{AA}$ in solution. Only small parts of AA monomers or oligomers can conjugate directly to the GSH through sulfhydryl group. The whole probable scavenging reactions of AA in the presence of GSH were described in Scheme 4 in detail.

\section{Conclusions}

In this work, the scavenging reaction of $\mathrm{AA}$ in the presence of GSH in vitro has been investigated using ESI/ MS. The study showed that parts of GSH molecule mainly degraded to the small molecular amino acids (glycine) fragment which was further degraded by the Streck degradation to form reactive aldehydes. The degradation products of glycine could react effectively with AA monomers and scavenge it. The $\mathrm{MS}^{\mathrm{n}}$ data supported that GSH molecules also contribute to the AA scavenging reaction by conjugating with AA through the sulfhydryl group in cysteine moiety as in the case of in vivo. ${ }^{2}$ The results obtained in the present work demonstrate the predictive power of ESI/MS and its successful application in the structural characterization of scavenging reaction of AA in the presence of GSH. Generally, human body takes GSH from food less than 100 $\mathrm{mg}$ daily depending on the diet. The experimental results indicated that GSH from daily diet might make one of the direct scavenging agents of AA in food intake. Therefore, people are less at risk of cancer even with the intake of the AA rich food if moderate amount of GSH is ingested through food because GSH scavenges AA effectively before they are transformed to more toxic glycidamide by enzymatic reaction and cause cancer.

Acknowledgments. The authors gratefully acknowledge the support by the Korea Research Foundation (Grant No. KRF 2003-041-C20183).

\section{References}

1. Pausson, B.; Granath, F.; Grawe, J.; Ehrenberg, L.; Tornqvist, M. Carcinoginisis 2001, 22, 817.

2. Friedman, M. A. J. Agric. Food Chem. 2003, 51, 4504.

3. Friedman, M. A.; Dulak, L. H.; Stedman, M. A. Fundam. Appl. Toxicol. 1995, 27, 95.

4. Park, J.; Kamendulis, L. M.; Friedman, M. A.; Klaunig, J. E. Toxicol. Sci. 2002, 65, 177.

5. Tareke, E.; Rydberg, P.; Karlsson, P.; Eriksson, S.; Tornqvist, M. Chem. Res. Toxicol. 2000, 13, 517.

6. Mottram, D. S.; Wedzicha, B. L.; Dodson, A. T. Nature 2002, 419, 448.

7. Pedreschi, F.; Kaack, K. Food Sci. Technol. 2004, 37, 679.

8. Yaylayan, V. A.; Wnorowski, A.; Carolina, P. L. J. Agric. Food Chem. 2003, 51, 1753.

9. Svensson, K.; Abramsson, L.; Becker, W.; Glynn, A.; Hellena, K E.; Lind, Y.; Rose, J. Food and Chemical Toxicology 2003, 41, 1581.

10. Varoujan, A. Y.; Aanrzej, W.; Carolina, P. L. J. Agric. Food Chem. 2003, 51, 1753 .

11. Tareke, E.; Rydberg, P.; Karlsson, P.; Eriksson, S.; Tornqvist, M. $J$. Agric. Food Chem. 2002, 50, 4998.

12. Stadler, R. H.; Blank, I.; Varga, N.; Robert, F.; Hau, J.; Guy, P.; Robert, M. C.; Riediker, S. Nature 2002, 419, 449.

13. Motram, D. S.; Wedzicha, B. L.; Dodson, A. T. Nature 2002, 419, 448.

14. Yaylayan, V. A.; Wronowski, A. J. Agric. Food Chem. 2000, 48 , 3549.

15. Mucci, L. A.; Dickman, P. W.; Steineck, G.; Adami, H. O.; Augustsson, K. British Journal of Cancer 2003, 88, 84.

16. Goncalo, G. C.; Mona, I. C.; Patrice, L; Linda, S.; Frederick, B. 
A.; Matilde, M.; Daniel, R. D. Chem. Res. Toxicol. 2003, 16, 1328.

17. Bull, R. J.; Robinson, M.; Laurie, R. D.; Stoner, G. D.; Greisiger, E.; Meier, J. R. Cancer Res. 1984, 44, 107.

18. Detlef, S.; Sophie, H. Rapid Commun. Mass Spectrom. 1998, 12, 273.

19. Weixing, S.; Junqiu, L.; Mei, C.; Fengrui, S.; Shuying, L. Rapid Commun. Mass Spectrom. 1999, 13, 950.

20. Marjan, G.; Simon, M.; Anita, M.; Julija, B. V.; Joze, M. Rapid Commun. Mass Spectrom. 2002, 16, 1186.

21. Mike, J. M.; Teva, V.; Chris, L.; Marc, V. M.; Dirk, I. Journal of Experimental Botany 1998, 49, 649.

22. Simon, C.; Gamble, A. W.; Peter, S. G. J. Chem. Tech. Biotechnol.
1997, 68, 123.

23. Electrospray Ionization Mass Spectrometry; Cole, R. B., Ed.; John Wiley-VCH: New York; USA, 1997.

24. Lee, Y. I.; Jo, S. C.; Tao, W. A.; Cooks, R. G. Rapid Com. Mass Spectrom. 2001, 15, 484.

25. Park, S. Y.; Chun, M. S.; Song, J. S.; Kim, H. J. Bull. Korean Chem. Soc. 2005, 26(4), 575.

26. Muller, M.; Zechmann, B.; Zellnig, G. Protoplasma 2004, 223, 213.

27. Cai, X. M.; Chhabil, D. Rapid Commun. Mass Spectrom. 2005, $19,1$.

28. Barbara, H.; Maria, S. Cellular \& Molecular Biology Letters 2004, 9, 329. 